\title{
Cross-cultural adaptation of the instrument Readiness for Hospital Discharge Scale - Adult Form
}

\author{
Adaptação transcultural do instrumento Readiness for Hospital Discharge Scale - Adult Form \\ Adaptación transcultural del instrumento Readiness for Hospital Discharge Scale - Adult Form
}

\author{
Talita Honorato Siqueira', Vanessa da Silva Carvalho Vila', Marianne Elizabeth Weiss" \\ ' Pontifícia Universidade Católica de Goiás. Goiânia, Goiás, Brazil. \\ "Marquette University, College of Nursing. Milwaukee, Wisconsin, United States of America.
}

How to cite this article:

Siqueira TH, Vila VSC, Weiss ME. Cross-cultural adaptation of the instrument Readiness for Hospital Discharge Scale - Adult Form. Rev Bras Enferm [Internet]. 2018;71(3):983-91. DOI: http://dx.doi.org/10.1590/0034-7167-2017-0241

Submission: 04-06-2017 Approval: 08-09-2017

\begin{abstract}
Objective: to perform the cross-cultural adaptation of the Readiness for Hospital Discharge Scale - (RHDS) Adult Form for use in Brazil. Method: a methodological study was conducted in 2015, in Brazil's federal capital, following the eight stages scientifically established. Results: analysis proved the maintenance of semantic, idiomatic, cultural, and conceptual equivalences and kept both the face and content validity of the original version. The judging committee and the pre-test participants declared they understood the RHDS items and answer scale. Conclusion: the instrument is culturally adapted for Brazil and can be used as one of the stages for planning hospital discharge.
\end{abstract}

Descriptors: Nursing Methodology Research; Transitional Care; Continuity of Patient Care; Patient-Centered Care; Patient Discharge.

\section{RESUMO}

Objetivo: realizar a adaptação transcultural do Readiness for Hospital Discharge Scale - (RHDS) Adult Form para uso no Brasil. Método: estudo metodológico desenvolvido em 2015, na capital federal do Brasil, seguindo os oito estágios preconizados cientificamente. Resultados: a análise evidenciou a conservação das equivalências semântica, idiomática, cultural e conceitual e manteve a validade de face e de conteúdo da versão original. Tanto o comitê de juízes quanto os participantes do pré-teste reportaram compreender os itens e a escala de respostas do RHDS. Conclusão: o instrumento está adaptado culturalmente para o Brasil e poderá ser utilizado como uma das etapas do planejamento da alta hospitalar.

Descritores: Pesquisa Metodológica em Enfermagem; Cuidado Transicional; Continuidade da Assistência ao Paciente; Assistência Centrada no Paciente; Alta do Paciente.

\section{RESUMEN}

Objetivo: Realizar la adaptación transcultural de la Readiness for Hospital Discharge Scale (RHDS) - Adult Form para utilizarlo en Brasil. Método: Estudio metodológico desarrollado en 2015, en la capital federal de Brasil, siguiendo las ocho etapas recomendadas científicamente. Resultados: El análisis evidenció preservación de equivalencias semántica, idiomática, cultural y conceptual. Se mantuvo validez de apariencia y contenido de versión original. Tanto el comité de expertos como los participantes de la prueba piloto informaron comprensión de ítems y escala de respuestas de RHDS. Conclusión: El instrumento está adaptado culturalmente para Brasil, pudiéndoselo utilizar como una etapa de la planificación del alta hospitalaria.

Descriptores: Investigación Metodológica en Enfermería; Cuidado de Transición; Continuidad de la Atención al Paciente; Atención Dirigida al Paciente; Alta del Paciente. 


\section{INTRODUCTION}

Hospital discharge is not a single event, characterized only by the termination of hospitalization. It is a complex process that occurs throughout the hospital stay and involves the coordination of care between the multidisciplinary team, patients, patients' families, and community caregivers ${ }^{(1-4)}$.

The transition of care after hospital discharge requires intervention initiated early on, whose goal is to ensure a safe and effective transition, emphasizing the coordination and continuity of care, particularly among high-risk populations such as the elderly, people with chronic multi-morbidities, and individuals who need long-term, complex care ${ }^{(4-6)}$. Studies point out that for this population, hospital discharge may be responsible for half of the readmissions, which can be prevented. In general, there are gaps in the coordination of care, low compliance after discharge, and inadequate information given upon discharge ${ }^{(5)}$.

Researchers who dedicate themselves to understanding transitional care have assessed the effectiveness of a series of health interventions that can favor adequate information sharing among the healthcare team, patients and their family members engaged in the process of discharge and help reduce the number of readmissions ${ }^{(4-5,-79)}$. Among these interventions, adequate preparation for hospital discharge has shown promising results, for instance, reducing medication error rates, avoidable hospital readmissions and costs, and increasing patients' and their family members' satisfaction with the process of hospital discharge $\mathrm{e}^{(2-3,5-5-6,10)}$.

Preparation for discharge is defined as a complex and multidimensional construct that requires a multiprofessional assessment for decision making ${ }^{(2,11-12)}$. Assessing patients' readiness for hospital discharge has been identified as an essential component of this planning process and may be a predicting factor for readmission risk ${ }^{(8,11-14)}$. Studies that evaluated this construct showed that patients who reported low readiness for discharge posed a greater risk of complications at home, post-discharge coping difficulties, and readmissions ${ }^{(8,11,15)}$.

From patients' perspectives, the perception of readiness for discharge often differs from the evaluation by their formal and informal caregivers ${ }^{(1-4)}$. Therefore, assessing the readiness for this moment has been described as an effective intervention to guide the planning and help to prevent complications, in addition to fostering patients' and their family members' empowerment and engagement in self-managing this care transition phase $\mathrm{e}^{(4,6,16)}$.

The instrument Readiness for Hospital Discharge Scale (RHDS) is the only one available and disseminated in the academic environment to assess readiness for hospital discharge from the patients' perspective, with the potential to establish an evaluation of interventions prior to hospital discharge $\mathrm{e}^{(1-3,5,12,14,17-18)}$.

This instrument was developed by American researchers ${ }^{(12)}$ and has been adopted in different contexts. It has been translated and validated in psychometric terms for use in countries such as the United States ${ }^{(12-14,17)}$, Switzerland, ${ }^{(18-19)}$ and China ${ }^{(20)}$. It has proven to be a reliable instrument and, throughout the analysis process, it underwent adaptations to the different contexts to create a reliable outcome measure of discharge preparation ${ }^{(12,17-20)}$.
The implementation of this measurement in Brazil might mean a more complete evaluation of the construct "readiness for hospital discharge', which goes beyond the traditional biomedical model because it includes the measurement of aspects that are subjective clinical parameters. Thus, healthcare professionals will have an important tool at their disposal to establish a care plan that can prepare people effectively for the transition of care.

The RHDS can be used with a heterogeneous population of patients who are discharged from hospital ${ }^{(12)}$. It is a questionnaire with 23 items. Item 1 is a dichotomic question that asks patients whether they are ready for discharge or not. This question is not included in the total score of the scale. The other 22 items (items 2 to 23) are subdivided into four sub-scales: personal status (items 2-8), knowledge (items 9-16), coping ability (items 17-19), and expected support (items 20-23). In the sub-scale personal status, participants are invited to describe their physical and emotional conditions prior to the period of hospital discharge. The knowledge sub-scale checks the perception of the information needed and received and how much this information will be able to answer the common concerns and problems in the post-discharge period. Sub-scale coping ability refers to one's ability to self-manage their personal needs and health care after hospital discharge. Sub-scale expected support checks the availability of emotional support and continuity of care in the period of transition from the hospital to the patients' homes $^{(12)}$.

The RHDS has been stated as questions, scored in a Likert scale from 0 to 10. Items 01 (a dichotomic question [yes/no] on the readiness for discharge) and 06 (deleted from the instrument by the author in the newer versions of the RHDS) are not included to calculate the final score. Item 03 requires a reverse code before calculating the score of the scale. The RHDS total score must be calculated adding the question scores and dividing them by the number of items in the instrument. Therefore, the instrument's scores are stratified into: very high readiness (9-10); high readiness $(8-8,9)$; moderate readiness $(7-7,9)$; and low readiness $(<7)$. The internal consistency of the original version for the total scale was assessed by Cronbach's alpha, obtaining the value of $0.90^{(12)}$.

\section{OBJECTIVE}

To cross-culturally adapt the Readiness for Hospital Discharge Scale - (RHDS) Adult Form for use in Brazil, in view of the confirmation of research on the validity and reliability of the instrument ${ }^{(12,17-20)}$.

\section{METHOD}

\section{Ethical aspects}

This study was approved by the Research Ethics Committee of the Goiás Catholic University (PUC/Goiás) and followed all the current ethical and legal aspects of the Brazilian legislation for research involving human beings. All the participants signed a free and informed consent form.

\section{Study design, setting, and period}

A methodological, cross-sectional study was conducted in the inpatient unit of a large, public teaching hospital that 
serves the population living both in Brazil's Federal District and in other states.

Data were collected between the months of April and September 2015, using the structured interview technique, through the following instruments: a) socioeconomic characteristics and clinical aspects form; and b) questionnaire for semantic analysis, adapted for use in Brazil ${ }^{(25)}$. This tool was made up of questions related to the general impression on the RHDS and specific questions on the importance and difficulty of understanding each item, with answers obtained by multiple choice.

\section{Sample characteristics (inclusion and exclusion criteria)}

For the pre-test, 40 people who were hospitalized for treating chronic morbidities and their complications were selected. The inclusion criteria were as follows: individuals who were 20 years of age or older and whose prospective discharge was in 24 hours at the most.

Individuals under palliative care, with serious hearing deficit, and with language and/or cognitive deficit (i.e, unable to inform the address where they lived, the day of the week and the month, their age and date of birth), in addition to patients with prior psychiatric conditions in their medical records were excluded from this study.

\section{Protocol for cross-cultural adaptation}

Initially, for the cross-cultural adaptation process of the Readiness for Hospital Discharge Scale - Adult Form instrument, researchers requested permission from the main author of the scale. The author granted permission via an electronic document for the instrument to be tested in its Brazilian version, in a sample of adult people who were hospitalized for the treatment of chronic morbidities.

The cross-cultural adaptation followed international guidelines ${ }^{(21-23)}$ and consisted of the stages of translation, synthesis of the translations, evaluation by an expert committee, backtranslation, consensus on the English versions in comparison with the original version, submission and evaluation of the reports on the instrument to the author of the original version, semantic analysis of the items, and pre-test.

The instrument was translated by two independent bilingual translators, native speakers of Brazilian Portuguese, who received the RHDS original version (OV), in English, via email. One translator knew the concepts researched by the instrument and the other did not have knowledge of the studied subject. The two versions, translated from English into Brazilian Portuguese, were called Portuguese version 1 (PV-1) and Portuguese version 2 (PV-2).

In order to synthesize both translations, researchers and translators met and the two independent translations (PV-1 and PV-2) were then compared and analyzed. This process resulted in a single consensual translation report, called consensual Portuguese version 1 (CPV-1), which was submitted to evaluation by the expert committee. The evaluation by the committee was conducted soon after the creation of CPV-1. This strategy is recommended to avoid translation mistakes in the back-translation stage ${ }^{(24)}$.

The expert committee was made up of six people: three nurses and one physical therapist who are professors and researchers, and two nurses with experience in the care for adults with complex care needs. They were invited to participate based on the following criteria: having knowledge of the study theme, mastery of the Portuguese and English languages, and knowledge of the methodology for cross-cultural adaptation studies. The meeting of the specialists took place in stages: 1. Introduction of the objectives and definition of the methodology for evaluation and reaching consensus; 2. Handing of the consensual Portuguese version 1 and the original version; 3 . Reading of both versions and analysis, item per item, for comparison, checking their replicability, and analyzing the semantic, idiomatic, cultural, and conceptual equivalence of the items of the instrument. To reach a consensus, the criterion was agreement on $80 \%$ of the decisions (keeping or changing the translation) related to face and content validity; 4 . Writing of the RHDS second consensual version in the Portuguese language (CPV-2).

The back-translation of version CPV-2 of the RHDS was done by two translators in an independent way. The translators were selected based on the following criteria: having American nationality, mastery of the American English language and Brazilian Portuguese, knowledge of the Brazilian and American cultures, and no previous knowledge of the studied subject. One of the translators had experience with scientific papers in the health area. Both versions translated from Brazilian Portuguese into American English were called English version 1 (EV-1) and English version 2 (EV-2).

To synthesize both translations, researchers and translators of the fourth stage met to compare and analyze the two independent translations (EV-1 and EV-2) based on the original version, which resulted into a single back-translation report called the RHDS final English version (FEV). The meeting for consensus between translators and researchers was conducted in the following stages: 1. Introduction of study goals and definition of the methodology adopted for reaching consensus; 2. Handing researchers and translators the instrument for comparison of the translations made (EV-1 and EV-2) together with the original version (OV) of the RHDS and CPV-2; 3. Reading of the three versions and analysis, item per item, for comparison, checking for the occasional need for changes, and discussion on the suitability of the back-translations; 4. Writing of the RHDS final English version (FEV) and review of the CPV-2, which resulted in the consensual Portuguese version 3 (CPV-3). The final English version (FEV) of the RHDS was submitted to the author of the original version. After evaluating it, she approved the FEV.

Throughout the process of cross-cultural adaptation, the RHDS face and content validity referring to its understandability, acceptance, and sensitivity of the items, respectively, by both the researchers and participants were tested based on subjective judgments by each of the expert committee members during the translation and adaptation process. At that moment, the experts gave the instrument its semantic, idiomatic, cultural, and conceptual equivalences.

After that, and before the pre-test, the semantic evaluation was done to check the understandability of the instrument's instructions, items, and answer scale by the RHDS targetpopulation. During this stage, the CPV-3 was applied to two groups of patients who experienced hospital discharge: group 
A (individuals with lower formal educational level) and group B (individuals with higher formal educational level), both made up of four patients selected by convenience, according to the study's inclusion and exclusion criteria. The members of each group received information concerning the goals of the study. After reading it, they signed the free consent form. In this stage the acceptance, relevance, and understanding of the items and answer scale were checked to evaluate the instrument and make it available for pre-test.

The pre-test of the RHDS CPV-3 was conducted with a sample selected by convenience, following the recommendations for this stage regarding cultural adaptation processes ${ }^{(21-23)}$. In this phase, the assessment instrument for the semantic analysis stage was also used, in addition to the criterion of agreement on $80 \%$ of the decisions regarding the face and content validity. Each item was slowly read and in case the participant did not understand it, the question was read twice. At the end of this stage, researchers came to the final version in Brazilian Portuguese (PFV-Br), called Readiness for Hospital Discharge Scale - (RHDS) Adult Form Brazilian version (RHDS-Br).

\section{Analysis of results and statistics}

In the pre-test stage, researchers did descriptive analyses of simple frequency (categorical variables), of central tendency (mean and median), and dispersion (standard deviation, minimum and maximum) to characterize the group studied. The data concerning this stage were processed and analyzed using IBM software Statistical Package for the Social Sciences (SPSS) for Windows, version 22.0.

\section{RESULTS}

During the evaluation of the synthesis of initial CPV-1 translation, the expert committee thoroughly discussed the following terms: "medical needs" (item 11), "problems to watch" (item 12), "follow-up medical treatment plan" (item 15), "medical treatments" (item 19), and "medical care needs" (item 23) because their respective translations pointed out to cultural differences for understanding their meaning in the Brazilian clinical context. To establish idiomatic equivalence, after the agreement of $80 \%$ of the experts, the following translations were defined: medical needs - health-related needs; problems to watch - problems you must pay attention to; follow-up treatment plan - continuity of one's medical treatment; medical treatments - health care treatment; medical care needs - healthcare-related needs. These aspects were also discussed, via e-mail, with the author of the instrument, who pointed to idiomatic differences in the meaning of medical needs and medical care and agreed with the translation defined by the expert committee.

To reach consensus on the back-translations, researchers and translators checked for idiomatic inconsistencies in items related to the continuity of one's treatment (item 15) and healthcare-related needs (item 23) in the CPV-2. This procedure required the rewriting of questions related to these items for the consensual Portuguese version 3 (CPV-3), which was then translated into English. This final version in English was sent by email to the instrument's main author for her appreciation. She agreed to the presented version and highlighted the accuracy of the instrument's cross-cultural adaptation process.

During the general evaluation in the semantic analysis stage, which does not depend on participants' formal educational level, eight participants classified the instrument as good. They did not have problems to answer the answer scale, considered the questions important for the evaluation of their readiness for hospital discharge, and did not suggest changes in the questions. Three people considered the questions easy; five said the questions were neither easy nor difficult; and seven would not add any questions. One participant would add one question regarding nutritional guidelines. This patient has had cardiovascular problems for 28 years and mentioned that, had he received guidance on nutritional aspects since the onset of his disease, he would have avoided many hospitalizations and would not have had so many changes in his laboratory tests.

In the specific evaluation stage, researchers identified participants' problems in understanding the following items: 1. When you think of hospital discharge, do you think you are ready to go home as planned? ; 5. How would you describe your energy today?

Another aspect pointed out by the participants was the perception that some items seemed to have the same meaning, such as: 8 . How would you describe your physical ability to care for yourself today, for example as regards personal hygiene, walking, and going to the bathroom? 9. How much do you know about caring for yourself after you go home? 10. How much do you know about caring for your personal needs (for example: personal hygiene, showering, going to the bathroom, eating) after you go home? 18 . Will you be able to adequately perform your personal care, for example as regards personal hygiene, showering, going to the bathroom, and eating, after you go home?

Keeping in mind that this was an initial stage of the study and the fact that the participants did not suggest rewriting the items, there was a choice for keeping the CPV-3 to be submitted to pre-test, the last stage of the cultural adaptation process.

The pre-test was applied to a sample of 40 people. Most of them $(72.5 \%)$ lived in the Federal District and $52.5 \%$ were male. The mean age of the group was 57.4 years $(S D=17.87$; $\mathrm{Cl}$ : 51.66 - 63.09). The youngest participant was 23 years old and the oldest, 84. As far as schooling was concerned, $45 \%$ of the participants had attended elementary school and the mean length of study was 6.8 years $(S D=5.30 ; C l: 5.10$ $8.50)$, varying between zero and 18 years. Some participants did not finish elementary school. The majority $(67.5 \%)$ said their monthly family income was up to one minimum salary. The minimum income was BRL 500.00, the maximum income was BRL 9,456.00, and the mean was BRL 2,113.77 $(\mathrm{SD}=1,841.73 ; \mathrm{Cl}: 1,481.12$ - 2,746.43).

Researchers observed that the conceptual understanding of some questions was difficult, namely: item 5 - How would you describe your energy today? ; item 16 - How much do you know about services and information available in your neighborhood after you go home?; item 21 - How much help will you have with your personal care after you go home? 
In the general evaluation of CPV-3, 85\% of the participants considered the instrument good and $15 \%$ considered it neither good nor bad. To $37.5 \%$ of the participants, the questions were easy and $62.5 \%$ said they were neither easy nor difficult. Regarding the difficulty to answer the scale, $2.5 \%$ had some difficulty, $20 \%$ had more or less difficulty, and $77.5 \%$ did not have any difficulty. All the participants $(n=40)$ considered the questions important to evaluate their readiness for discharge and stated they did not have any objections to answering any items of the instrument. Only $10 \%$ of the participants said they desired to add questions on the educational aspects regarding nutrition, treatment, and treatment continuity.

As the participants of the pre-test showed acceptance, evaluated the items as important and did not suggest any rewritings, the CPV-3 was then called RHDS-Br - preliminary version for use in Brazil (Chart 1).

Chart 1 - Preliminary version of the "Readiness for Hospital Discharge Scale" (RHDS-Br) for use in Brazil, Brasilia, Federal District, 2014

\section{Questions of the preliminary version for use in Brazil}

\begin{tabular}{|c|c|}
\hline \multicolumn{2}{|c|}{ Questions of the preliminary version for use in Brazil } \\
\hline Item 1 - Readiness for discharge & $\begin{array}{l}\text { When you think about leaving the hospital, do you believe that you are ready to go } \\
\text { home as planned? }\end{array}$ \\
\hline \multicolumn{2}{|r|}{ Sub-scale - Personal status } \\
\hline Item 2 - Physical readiness & How physically ready are you to go home? \\
\hline Item 3 - Pain / discomfort & How would you describe your pain or discomfort today? \\
\hline Item 4 - Strength & How would you describe your strength today? \\
\hline Item 5 - Energy & How would you describe your energy level today? \\
\hline Item 6 - Stress & How much stress do you feel today? \\
\hline Item 7 - Emotional preparation & How emotionally ready are you to go home today? \\
\hline Item 8- Physical capacity for self-care & $\begin{array}{l}\text { How would you describe your physical ability to care for yourself today (for example: } \\
\text { personal hygiene, walking, going to the bathroom)? }\end{array}$ \\
\hline \multicolumn{2}{|r|}{ Sub-scale - Knowledge } \\
\hline Item 9 - Knowledge about self-care & How much do you know about taking care for yourself, after you go home? \\
\hline Item 10- Knowledge of personal needs & $\begin{array}{l}\text { How much do you know about taking care of your personal needs (for example: personal } \\
\text { hygiene, taking a bath, going to the bathroom, feeding yourself) after you go home? }\end{array}$ \\
\hline Item 11 - Knowledge of health needs & $\begin{array}{l}\text { How much do you know about taking care of your health-related needs (treatments, } \\
\text { medications) after you go home? }\end{array}$ \\
\hline Item 12 - Knowledge of complications & $\begin{array}{l}\text { How much do you know about any problems to which you must pay attention to after } \\
\text { you go home? }\end{array}$ \\
\hline Item 13 - Knowledge of who and when to call & $\begin{array}{l}\text { How much do you know about who to call and when to call if you have any problems } \\
\text { after you go home? }\end{array}$ \\
\hline Item 14 - Knowledge of restrictions & $\begin{array}{l}\text { How much do you know about any restrictions (what you can or cannot do) after you go } \\
\text { home? }\end{array}$ \\
\hline Item 15 - Knowledge of the next steps of treatment & How much do you know about the next stage of your treatment after you go home? \\
\hline Item 16 - Knowledge of resources & $\begin{array}{l}\text { How much do you know about the services and information available in your } \\
\text { community after you go home? }\end{array}$ \\
\hline \multicolumn{2}{|r|}{ Sub-scale - Coping ability } \\
\hline Item 17 - Ability to perform day-to-day tasks & How well will you be able to cope with day-to-day life at home? \\
\hline Item 18 - Ability to care for self & $\begin{array}{l}\text { Will you be able to perform your personal care properly (for example: personal hygiene, } \\
\text { bathing, feeding yourself) when you are at home? }\end{array}$ \\
\hline Item 19 - Ability to care for health & $\begin{array}{l}\text { How well will you be able to perform your own healthcare treatment (for example: } \\
\text { caring for surgical wounds, respiratory treatments, exercise, rehabilitation, taking the } \\
\text { right amount of medicine at the right time) at home? }\end{array}$ \\
\hline
\end{tabular}




\begin{tabular}{|l|l|}
\hline \multicolumn{2}{|c|}{ Questions of the preliminary version for use in Brazil } \\
\hline Item 20 - Emotional support & \multicolumn{1}{|c|}{ Sub-scale - Expected support } \\
\hline Item 21 - Help with personal care & How much emotional support will you have after you go home? \\
\hline Item 22 - Help with domestic activities & How much help will you have with your personal care after you go home? \\
\hline Item 23 - Help with health-related needs & $\begin{array}{l}\text { When you go home, how much help will you have to perform household activities (for } \\
\text { example: cooking, cleaning, shopping, childcare)? }\end{array}$ \\
\hline
\end{tabular}

\section{DISCUSSION}

This study introduces in the Brazilian context the possibility to evaluate and measure the construct readiness for hospital discharge through a standardized instrument. Although the results are related to its preliminary version, researchers observed that the instrument presents an important conceptual model and demonstrates adequate content to assess readiness for hospital discharge, from the perspective of adult and older people who experience the transition in care from the hospital to the home context ${ }^{(14,18)}$.

It is understood that the conceptual model of readiness for discharge involves, in an interdependent way, the planning for this moment (evaluation and planning for needs of care upon discharge and estimation of the readmission risk), the coordination of discharge (organization for any need of support after discharge), and education for discharge (educational interventions) ${ }^{(2)}$. Based on this conception, the RHDS consists of a measurement assessment of the readiness for hospital discharge and has been adopted not only as a quality indicator for planning the return home, but also to identify, prior to discharge, the patients with high readmission risk ${ }^{(12-13,17-18)}$.

Assessing readiness for discharge is an opportunity to get patients' data from their own account in terms of their immediate physical status and their perceived abilities to manage their healthcare needs in the context of home, in addition to enabling the identification of possible hindrances for the continuity of care $^{(12,14)}$.

Researchers claim that through this evaluation, the multiprofessional team has the chance to establish therapeutic plans whose goals are to prepare patients and their families for discharge, in addition to identifying the demands needed for a suitable coordination in the continuity of care among the various levels of health care ${ }^{(10,18,26)}$. Clinical nurses are the leaders in charge of patients' discharge; therefore, it is their responsibility to assess the needs for care in terms of readiness for the post-discharge period. They are also responsible for ensuring the quality of readiness before patients are formally discharged from the hospital ${ }^{(17)}$.

Researchers realized that the questions elaborated in the process of creating this instrument include aspects that involve transitional care and have a strong emphasis on assessment and planning the interventions for hospital discharge to improve: (1) physiological stability, (2) self-management ability,
(3) self-efficacy to deal with the transition of care, (4) availability of social support and (5) one's capacity to access community resources ${ }^{(14,18)}$.

The results of the cross-cultural adaptation process and the application of the pre-test of the RHDS-Br preliminary version had satisfactory answers in terms of conceptual-semantic equivalence with the categorized items in the instrument in the dimensions physical status, knowledge, coping ability, and expected social support.

Throughout this process, some adaptations were needed in the writing of items that contained expressions related to the adjective "medical" (items 11, 15, 19, and 23). There was a consensus among researchers and in agreement with the author of the instrument that this term, in the Portuguese language, involves the concept of aspects pertaining to health care rather than referring solely to the medical treatment.

Both in the semantic validation phase and during pre-test, researchers realized that the difficulty in understanding the questions that addressed the concept of energy and self-care capacity demanded additional explanations from interviewers to be properly understood by the patients. The same was seen in the cross-cultural adaptation study of the RHDS for the Swiss context (French language) ${ }^{(19)}$. Researchers stated that this concept was not completely understood because for the Swiss population, the concept of energy is often associated with objects. Regarding item 21, help for self-care, the authors claimed that the question was not written clearly enough for the participants: it was too long and difficult to understand.

In the Brazilian reality, like described in an Irish study ${ }^{(16)}$ that used this instrument, the assessment of readiness was only possible in the case of people whose discharge was predicted for a 24-hour period. However, it was possible to verify that the definition of hospital discharge often occurred without the corresponding entry in the medical records. That hindered the recruitment and made it more difficult to follow the recommendations for the application of the instrument, which states it should be applied approximately four hours before hospital discharge $\mathrm{e}^{(14)}$. This aspect suggests there are deficits in the planning of hospital discharge that disfavor various patients' needs and hinder educational actions in favor of patients' engagement in managing the transition of care. These aspects deserve to be looked at more closely in future scientific studies.

Some questions related to the capacity to care for one's own health addressed in three dimensions were perceived as 
similar in terms of assessing physical status (item 8), knowledge (items 9 and 10), and ability to perform personal health care (item 18). Although this aspect was observed, as in other studies that translated this instrument, researchers chose to keep the theoretical structure initially conceived by the authors of the scale. The preliminary version after the evaluation of the pre-test was analyzed in psychometric terms and these findings will be presented in due course. Possibly, as it was also observed in the studies conducted in the United States $^{(12,14,18)}$, Ireland ${ }^{(16,18)}$, Switzerland, ${ }^{(18-19,26)}$ and China ${ }^{(20)}$, these questions might be excluded, through a psychometric analysis, from the Brazilian instrument's final version in the ongoing validation stage.

The process of cross-cultural adaptation consisted of an important methodologic stage because, in addition to producing a tool with the perspective of being incorporated into the discharge planning protocols in the Brazilian context, it initiated the conceptual reflection on the construct readiness and the way discharge has been dealt with in different places of care.

Studies of this nature enable researchers, translators, and committees of specialists, through a solid process that involves reading and evaluating the translations produced in multiple stages, to identify idiomatic aspects and promote semantic and conceptual adaptations referring to the studied construct. This demands team work and dialog, a process where the understanding of the measurement emerges from interpretations contained in the questions created for the instrument. It is also indispensable in this process to establish a complex coordination among the dimensions that make up the construct to be operationalized in a standardized measure.

\section{Study limitations}

Based on the results of the cross-cultural adaptation of the RHDS instrument for Brazil, researchers identified the potential to use this tool. The presented results refer to the pre-test stage and require the analysis of the instrument's psychometric properties for its validation, which is ongoing. Up to this point, the evidence points out to the need for further research to verify the RHDS structure and deepen the theoretical explanation for this construct in the cultural context where it will be used.
Contributions for the Nursing, health or public policy areas

Researchers believe that the use of this tool will help improve the quality of discharge planning, as well as the interventions needed for the preparation of patients and caregivers. This instrument can also favor the identification of patients who lack adequate preparation in terms of their physical well-being, knowledge, and self-management and coping abilities, or of those who do not have social support for their recovery after hospital discharge $\mathrm{e}^{(14,18-19,26)}$. Moreover, it is an important tool to establish a care plan that can effectively prepare people for the transition of care. This must include additional educational interventions with patients and their families, case management, referrals for the continuity of care at community facilities, and patient monitoring through phone calls and visits ${ }^{(1,3,5,11,26)}$.

\section{CONCLUSION}

The instrument Readiness for Hospital Discharge Scale (RHDS-Br) is culturally adapted for Brazil and may be used as one of the stages for planning hospital discharge, given its potential to become a guideline to establish therapeutic goals and interventions that include the demands of transitional care, an aspect that favors the quality and safety of this process.

The results of the cross-cultural adaptation of the RHDS-Br showed that this instrument maintained its semantic, idiomatic, cultural, and conceptual equivalences and the face and content validity of the original version, according to the evaluation by the expert committee.

The psychometric analysis to create its final version is ongoing; however, in conceptual terms, researchers could realize that the construct readiness for hospital discharge is important to establish a discharge planning protocol to deal with the needs of people at high risk of readmission due to clinical situations or incapacity for the continuity of the therapeutic plan in the period of transition of care.

\section{FUNDING}

The Goiás Research Foundation (Fundação de Amparo à Pesquisa do Estado de Goiás - FAPEG) funded this study through a Master's program scholarship.

\section{REFERENCES}

1. Coleman EA, Boult C, American Geriatrics Society Health Care Systems C. Improving the quality of transitional care for persons with complex care needs. J Am Geriatr Soc [Internet]. 2003 [cited 2017 Apr 06];51(4):556-7. Available from: https://www.ncbi. nlm.nih.gov/pubmed/12657079

2. Weiss ME, Bobay KL, Bahr SJ, Costa L, Hughes RG, Holland DE. A model for hospital discharge preparation: from case management to care transition. J Nurs Adm [Internet]. 2015 [cited 2017 Apr 06];45(12):606-14. Available from: https://www.ncbi.nlm.nih.gov/ pubmed/26502068

3. Naylor MD, Aiken LH, Kurtzman ET, Olds DM, Hirschman KB. The care span: the importance of transitional care in achieving health reform. Health Aff (Millwood) [Internet]. 2011 [cited 2015 Aug 22];30(4):746-54. Available from: http://content.healthaffairs. org/content/30/4/746.full.pdf + html

4. Coleman EA, Parry C, Chalmers S, Min SJ. The care transitions intervention: results of a randomized controlled trial. Arch Intern Med [Internet]. 2006 [cited 2016 Mar 06];166(17):1822-8. Available from: http://jamanetwork.com/journals/jamainternalmedicine/ fullarticle/410933 
5. Snow V, Beck D, Budnitz T, Miller DC, Potter J, Wears RL, et al. Transitions of care consensus policy statement: American College of Physicians, Society of General Internal Medicine, Society of Hospital Medicine, American Geriatrics Society, American College Of Emergency Physicians, and Society for Academic Emergency Medicine. J Gen Intern Med [Internet]. 2009 [cited 2016 Oct 01];24(8):9716. Available from: https://hospitalmedicine.ucsf.edu/improve/literature/transitions_of_care_consensus_policy_statement_jhm.pdf

6. Gonçalves-Bradley DC, Lannin NA, Clemson LM, Cameron ID, Shepperd S. Discharge planning from hospital to home. Cochrane Database Syst Rev [Internet]. 2013 [cited 2017 Apr 03];(1):CD000313. Available from: http://onlinelibrary.wiley.com/ doi/10.1002/14651858.CD000313.pub5/epdf

7. Ottenbacher KJ, Karmarkar A, Graham JE, Kuo Y-F, Deutsch A, Reistetter TA, et al. Thirty-day hospital readmission following discharge from postacute rehabilitation in fee-for-service medicare patients. JAMA [Internet]. 2014 [cited 2015 Mar 12];311(6):60414. Available from: https:/www.ncbi.nlm.nih.gov/pmc/articles/PMC4085109/pdf/nihms568694.pdf

8. Weiss ME, Yakusheva O, Bobay KL. Quality and cost analysis of nurse staffing, discharge preparation, and postdischarge utilization. Health Serv Res [Internet]. 2011 [cited 2015 Mar 12];46(5):1473-94. Available from: https://www.ncbi.nlm.nih.gov/pmc/articles/ PMC3207188/pdf/hesr0046-1473.pdf

9. Van Walraven C, Bennett C, Jennings A, Austin PC, Forster AJ. Proportion of hospital readmissions deemed avoidable: a systematic review. CMAJ [Internet]. 2011 [cited 2016 Mar 30];183(7):E391-402. Available from: https://www.ncbi.nlm.nih.gov/pmc/articles/ PMC3080556/pdf/183e391.pdf

10. Nosbusch JM, Weiss ME, Bobay KL. An integrated review of the literature on challenges confronting the acute care staff nurse in discharge planning. J Clin Nurs [Internet]. 2011 [cited 2017 Apr 06];20(56):754-74. Available from: https://www.ncbi.nlm.nih. gov/pubmed/20955476

11. Harrison JD, Greysen RS, Jacolbia R, Nguyen A, Auerbach AD. Not ready, not set...discharge: patient reported barriers to discharge readiness at an academic medical center. J Hosp Med [Internet]. 2016 [cited 2017 Apr 06];11(9):610-4. Available from: https:// www.ncbi.nlm.nih.gov/pubmed/27079295

12. Weiss ME, Piacentine LB. Psychometric properties of the readiness for hospital discharge scale. J Nurs Meas[Internet]. 2006 [cited 2017 Apr 06];14(3):163-80. Available from: http://www.ingentaconnect.com/content/springer/nmeas/2006/00000014/00000003/ art00002

13. Weiss M, Yakusheva O, Bobay K. Nurse and patient perceptions of discharge readiness in relation to postdischarge utilization. Med Care [Internet]. 2010 [cited 2017 Apr 06];48(5):482-6. Available from: https://www.ncbi.nlm.nih.gov/pubmed/20393364

14. Weiss ME, Piacentine LB, Lokken L, Ancona J, Archer J, Gresser S, et al. Perceived readiness for hospital discharge in adult medical-surgical patients. Clin Nurse Spec [Internet]. 2007 [cited 2017 Apr 06];21(1):31-42. Available from: https://www.ncbi. nlm.nih.gov/pubmed/17213738

15. Knier S, Stichler JF, Ferber L, Catterall K. Patients' perceptions of the quality of discharge teaching and readiness for discharge. Rehabil Nurs [Internet]. 2015 [cited 2017 Apr 06];40(1):30-9. Available from: https://www.ncbi.nlm.nih.gov/pubmed/24962625

16. Coffey A, McCarthy GM. Older people's perception of their readiness for discharge and postdischarge use of community support and services. Int J Older People Nurs [Internet]. 2013 [cited 2017 Apr 06];8(2):104-1. Available from: https://www.ncbi.nlm.nih. gov/pubmed/22309350

17. Weiss ME, Costa LL, Yakusheva O, Bobay KL. Validation of patient and nurse short forms of the readiness for hospital discharge scale and their relationship to return to the hospital. Health Serv Res [Internet]. 2014 [cited 2016 Mar 16];49(1):304-17. Available from: https://www.ncbi.nlm.nih.gov/pmc/articles/PMC3922479/

18. Mabire C, Coffey A, Weiss M. Readiness for hospital discharge scale for older people: psychometric testing and short form development with a three country sample. J Adv Nurs [Internet]. 2015 [cited 2017 Apr 06];71(11):2686-96. Available from: http:// onlinelibrary.wiley.com/doi/10.1111/jan.12731

19. Mabire C, Lecerf T, Büla C, Morin D, Blanc G, Goulet C. Translation and psychometric evaluation of a french version of the readiness for hospital discharge scale. J Clin Nurs [Internet]. 2015 [cited 2017 Apr 06];24(19-20):2983-92. Available from:https:// www.ncbi.nlm.nih.gov/pubmed/26216599

20. Zhao H, Feng X, Yu R, Gu D, Ji X. Validation of the chinese version of the readiness for hospital discharge scale on patients who have undergone laryngectomy. J Nurs Res [Internet]. 2016 [cited 2017 Apr 06];24(4):321-8. Available from: https://www.ncbi.nlm. nih.gov/pubmed/27846104

21. Beaton D, Bombardier C, Guillemin F, Ferraz MB. Recommendations for the cross-cultural adaptation of the DASH \& QuickDASH outcome measures. Instit Work Health [Internet]. 2007 [cited 2016 Mar 06]. Available from: http://www.dash.iwh.on.ca/sites/ dash/files/downloads/cross cultural adaptation 2007.pdf

22. Beaton DE, Bombardier C, Guillemin F, Ferraz MB. Guidelines for the process of cross-cultural adaptation of self-report measures Spine [Internet]. 2000 [cited 2017 Apr 06];25(24):3186-91. Available from: https://www.ncbi.nlm.nih.gov/pubmed/11124735

23. Ramada-Rodilla JM, Serra-Pujadas C, Delclos-Clanchet GL. Cross-cultural adaptation and health questionnaires validation: revision and methodological recommendations. Salud Publica Mex [Internet]. 2013[cited 2016 Oct 01];55(1):57-66. Available from: http://www.scielosp.org/pdf/spm/v55n1/v55n1a09.pdf

24. Ferrer M, Alonso J, Prieto L, Plaza V, Monso E, Marrades R, et al. Validity and reliability of the St George's respiratory questionnaire 
after adaptation to a different language and culture: the spanish example. Eur Respir J[Internet]. 1996 [cited 2016 Oct 11];9(6):11606. Available from: http://erj.ersjournals.com/content/erj/9/6/1160.full.pdf

25. Fegadolli C, Reis RA, Martins STA, Bullinger M, Santos CBD. Adaptation of the generic DISABKIDS ${ }^{\circledR}$ module for Brazilian children and adolescents with chronic disorders. Rev Bras Saude Mater Infant [Internet]. 2010 [cited 2016 Oct 01];10(1):95-105. Available from: http://www.scielo.br/pdf/rbsmi/v10n1/v10n1a10.pdf

26. Mabire C, Büla C, Morin D, Goulet C. Nursing discharge planning for older medical inpatients in Switzerland: a cross-sectional study. Geriatr Nurs [Internet]. 2015 [cited 2017 Apr 06];36(6):451-7. Available from: http://www.gnjournal.com/article/ S0197-4572(15)00236-0/pdf 